\title{
A Silent or Hypo-symptomatic Disease Can Erupt: Acute Presentations of Celiac Disease
}

\author{
Aaron Lerner ${ }^{1,2, *}$, Torsten Matthias ${ }^{2}$ \\ ${ }^{1}$ B. Rappaport School of Medicine, Technion-Israel Institute of Technology, Haifa, Israel \\ ${ }^{2}$ AESKU.KIPP Institute, Wendelsheim, Germany \\ *Corresponding author: aaronlerner1948@gmail.coml
}

\begin{abstract}
Celiac disease is a multi-organ disorder which is highly variable in its clinical expression, presenting multiple enteric and extraintestinal manifestations. However, most of treating physicians and dieticians regard celiac disease as a chronic, gradually evolving, asymptomatic or hypo-symptomatic entity. The present mini-review aims to screen the literature for acute presentations of celiac disease and to increase the awareness of the medical communities, for such a possibility. It appears that the disease can present acutely in multiple symptomatic, phenotypic and laboratory pictures. The acute presentation involves mainly the gastrointestinal tract and adjacentorgans like liver and gallbladder, however, extraintestinal and remote organs presentations can occur.
\end{abstract}

Keywords: celiac disease, acute, presentation

Cite This Article: Aaron Lerner, and Torsten Matthias, "A Silent or Hypo-symptomatic Disease Can Erupt: Acute Presentations of Celiac Disease." International Journal of Celiac Disease, vol. 5, no. 4 (2017): 129-132. doi: 10.12691/ijcd-5-4-1.

\section{Introduction}

Celiac disease (CD) is an autoimmune disorder elicited in genetically predisposed individuals by the consumption of gluten-containing grains (i.e. wheat, barley, rye and oat) or ingredients of them.It is generally accepted that CD affects approximately $1-1.5 \%$ of Western populations, whereby in Northern European countries like Sweden, Finland and Ireland the incidence is higher, thus fitting the North to South incidence gradient [1]. Even in the Far East, where rice is the main staple food, increased incidence of $\mathrm{CD}$ is being reported. In India, for example, the prevalence of $\mathrm{CD}$ in the general pediatric population attending a tertiary care hospital of North India mounted to $1 \%$. [2] and the question: can we avert the impending epidemic of CD in India? Thisis highly vindicated [3]. China, however, presents a comparable incidence to the Western world only in high risk populations, but in the normal population it is much lower, not reaching even $0.5 \%$. $[4,5]$. In recent years, an increasing number of $C D$ patients have been identified even in the Middle East and North Africa, where it was historically considered to be an extremely rare disorder [6]. Co-localization of gluten consumption, HLA-DQ2 and -DQ8 genotypes frequency and $\mathrm{CD}$ incidence reinforce the genetic and environmental interplay in CD progression [7].

In fact, $C D$ is actually a multi-organ disorder which is highly variable in its clinical expression, presentingmultiple enteric and extraintestinal manifestations [8]. For these reasons the diagnosis is often delayed.

Currently, we are witnessing a diffused ongoing endemic of $\mathrm{CD}$ of great scale. Epidemiological data provides strong evidence of a steady rise of the disease throughout Westernized societies over the last six decades [1]. The reasons for this worldwide surge in CD incidenceare multiple and debatable (Table 1).

Table 1. Summary of the potential explanation for CD incidence surge $[1,9,10,11,12]$

\begin{tabular}{|l|}
\hline Suggested raisons for the increased incidence of celiac disease \\
\hline Increased prolamins intake \\
\hline Higher gluten content in modern wheat \\
\hline Higher toxicity of gluten in modern wheat \\
\hline Gluten is autoimmunogenic \\
\hline Gluten is potentially detrimental to humankind \\
\hline Increased production of wheat per hectare \\
\hline Increased environmental inducers of CD: stress, infections \\
\hline Associate dysbiome \\
\hline Increased intestinal permeability by processed food additives \\
\hline Increased public and professional awareness \\
\hline Improved serological diagnosis \\
\hline Skipping intestinal biopsy as per ESPGHAN 2012 new criteria \\
\hline Genetic advantage and evolutionary survival of CD patients \\
\hline
\end{tabular}

Moreover, some patients have no symptoms at all despite the presence of characteristic intestinal lesions, while various atypical clinical manifestations and asymptomatic forms of $\mathrm{CD}$ means that most cases remain un- or misdiagnosed, with a 1:7 ratio of diagnosed to undiagnosed cases [13]. This has led to the concept of a "CD iceberg", with only the "tip" of the cases being seen [14]. Furthermore, undiagnosed CD patients cannot receive timely treatment, and will have an elevated risk for developing secondary autoimmune disorders (type 1 diabetes, Hashimoto thyroiditis, Addison's disease, autoimmune hepatitis, etc.) 
stunted growth, osteoporosis/osteopenia, infertility, increased morbidity and mortality as well as various malignancies [14].

Epidemiologically, it has been shown that the classic intestinal clinical picture of malnutrition, chronic diarrhea and nutritional deficiencies are disappearing and extraintestinal presentations are emerging. Skin, endocrine, skeletal, hepatic, hematological, thrombophilic, gynecological, fertility-related, dental, obesity, neurological and behavioral abnormalities are often described $[15,16,17]$. Today, we are witnessing an epidemiological shift in the disease phenotype toward a more advanced age, and increased prevalence of latent, hypo-symptomatic or asymptomatic behavior [15]. All these changes make the diagnosis of the disease more difficult and the reliance on symptomatology more remote. Most of treating physicians and dieticians regard $\mathrm{CD}$ as a chronic, gradually evolving, unnoticed,asymptomatic or hypo-symptomatic entity. In such a case, quite frequently, acute presentations are not considered and do not lead to bring up $\mathrm{CD}$ as a possibility. The present review aims to screenthe literature for acute presentations of $\mathrm{CD}$ and to increase the awareness of the medical communities for such a possibility.

\section{Acute Presentations of Celiac Disease}

Contrary to the accepted scientific and medical communities impression, CD can present acutely, in multiple symptomatic, phenotypic and laboratory pictures. More so, it is considered as a "1000 faces disease" with a very wide range of presentations, including acute ones. Table 2 lists some of them.

It is quite obvious that $\mathrm{CD}$ is not only a chronic, gradually evolving, unnoticed, asymptomatic or hypo-symptomatic entity. It can present acutely, involving mainly the gastrointestinal tract and adjacent organs like liver and gallbladder, notably, extraintestinal and remote organs presentations were also described.

\section{Discussion}

The present mini-review opens a hatch, showing that $\mathrm{CD}$ can present acutely, thus adding an additional aspect to the celiac clinical kaleidoscope. In view of the routine belief that $\mathrm{CD}$ presents mainly in a hypo- or asymptomatic ways, the health providing care teams should be aware of such acute presentations in a chronic disease like CD. Such a widen view might increase the diagnostic rate, impact the diagnosed/undiagnosed ratio and might advance initiation of gluten withdrawal.

It will be difficult or unethical to study the acute effects of gluten consumption, in vivo, on $\mathrm{CD}$ high risk people. Ex-vivo gluten application on gluten-free diet intestinal biopsy, bypass the obstacle. Many ex-vivo, in vitro models were described, using human originated intestinal cell-lines or CD patients small bowel mucosal biopsies $[41,42]$. We know nowadays that gluten or gliadin, when incubated with primary cultures of CD patients on glutenfree diet,induces morphological as well as immunological aberrations. Cytokine release, autoantibodies secretions, increased CD25+ cell density, MHC class 1 chain-related gene A expression were reported $[43,44]$. Applying genetic bioinformatics, it was shown that important dysfunction of pathogenic networks related to cell to cell communications, intracellular signaling, ubiquitin-proteasome system, cell cycle and apoptosis and extracellular matrix modulation resulted from acute gliadin effects on mucosal biopsies of CD patients, while on gluten withdrawal [45].

Those ex-vivo, acute effects of gluten/gliadin that are manifested during the first 48 hours of incubation, give us some mechanistic hints whereby $\mathrm{CD}$ can manifest in an acute clinical presentations. Additionally, the black box of the mucosal events occurring during accidental gluten exposure is unknown. Unravelling the pathogenesis of acute presentation of $\mathrm{CD}$, might open new comprehensive picture of key events contributing to $\mathrm{CD}$ initiation and progression.

Table 2. Summary of acute presentations of celiac disease

\begin{tabular}{|c|c|c|c|}
\hline & Acute presentation/manifestation & Organ involved & Reference \\
\hline 1 & Iron deficiency anemia & blood & 18 \\
\hline 2 & Folate deficiency anemia & blood & 19 \\
\hline 3 & Watery diarrhea & gastrointestinal & 20 \\
\hline 4 & Profound diarrhea and weight loss & gastrointestinal & 21 \\
\hline 5 & Celiac crisis & Multi-organ & $21-25$ \\
\hline 6 & Electrolyte imbalance & blood & $22-25$ \\
\hline 7 & Hepatitis & liver & 23 \\
\hline 8 & Hepatic failure & liver & 26 \\
\hline 9 & Intestinal Intussusception/invagination & intestine & $27-30$ \\
\hline 10 & Cholecystitis, lithiasis & gallbladder & 31,32 \\
\hline 12 & Status epilepticus, encephalopathy & neurological & 33 \\
\hline 13 & Malabsorption & intestinal & 34 \\
\hline 14 & Malnutrition & intestinal & 35,36 \\
\hline 15 & Infections & Liver, urinary tract & 23,37 \\
\hline 16 & After pregnancy & Gynecological & 38,39 \\
\hline 17 & Colonic pseudo-obstruction & Gastrointestinal-colon & 40 \\
\hline
\end{tabular}




\section{Conclusions}

Contrary to the accepted scientific and medical communities impression, $\mathrm{CD}$ can present acutely, in multiple symptomatic, phenotypic and laboratory pictures. More so, it is considered as a "1000 faces disease" with a very wide range of presentations, including acute ones. The acute presentation involves mainly the gastrointestinal tract and adjacentorgans like liver and gallbladder, however, extraintestinal and remote organs presentations can occur. The genetic as well as the environmental factors that contribute to an acute presentation in a CD patient await further exploration.

\section{References}

[1] Lerner A, Jeremias P, Matthias T. The world incidence of celiac disease is increasing: a review. Internat. J. Of Recent Scient. Res. 2015;7:5491-5496.

[2] Bhattacharya M, Dubey AP,Mathurindian NB. Prevalence of Celiac Disease in North Indian Children. Pediatrics 2009;465: 415-7.

[3] Ramakrishna BS. Celiac disease: can we avert the impending epidemic in India? Indian J Med Res. 2011;133:5-8

[4] Wang H, Zhou G, Luo L, J. Bart A. Crusius JBA, Yuan A, Kou J, et al. Serological Screening for Celiac Disease in Adult Chinese Patients with Diarrhea Predominant Irritable Bowel Syndrome. Medicine (Baltimore). 2015; 94: e1779.

[5] Juanli Yuan, Jinyan Gao, Xin Li, Fahui Liu, Cisca Wijmenga, Hongbing Chen, et al.The Tip of the "Celiac Iceberg" in China: A Systematic Review and Meta-Analysis. PLoS One. 2013; 8: e81151.

[6] Malekzadeh R, Sachdev A, Fahid Ali A (2005) Coeliac disease in developing countries: Middle East, India and North Africa. Best Pract Res Clin Gastroenterol 19: 351-358.

[7] Lionetti E, Catassi C. Co-localization of gluten consumption and HLA-DQ2 and -DQ8 genotypes, a clue to the history of celiac disease. Dig Liver Dis. 2014;46:1057-63.

[8] Lerner A, Matthias T. Extraintestinal manifestations of CD: Common pathways in the gut-remote organs' axes. Internat $\mathrm{J}$ Celiac Dis. 2017;5:24-27.

[9] Lerner A, Neidhöfer S, Matthias T. Serological markers and/or intestinal biopsies in the case-finding of celiac disease. Internat. $\mathrm{J}$ Celiac Dis. 2015;3:53-55.

[10] Lerner A, Matthias T. Gluten free diet- tough alley in torrid time. Internat J Celiac Dis. 2017;5:50-55.

[11] Lerner A. Balanced polymorphism: a survival advantage in celiac disease. Editorial. Medical Hypotheses, 2011;77:1-2.

[12] Lerner A. The last two millennias eco-catastrophes are the driving forces for the potential genetic advantage mechanisms in celiac disease. Med Hypotheses. 2011;77:773-6.

[13] Tommasini A, Not T, Kiren V, Baldas V, Santon D, Trevisiol C, et al. Mass screening for celiac disease using antihuman transglutaminase antibody assay. Arch Dis Child 2004; 89: 512-515.

[14] Lerner A. Serological Diagnosis of Celiac Disease -Moving Beyond the Tip of the Iceberg. Internat J Celiac Dis. 2014;2:64-66.

[15] Lerner A, Agmon-Levin N, Shapira Y, Gilburd B, Reuter S, Lavi L, Shoenfeld Y. The thrombophylic network of autoantibodies in celiac disease. BMJ Medicine, 2013,11;89-95.

[16] Eliyah Livshits O, Shauol R, Reifen R, Matthias T, Lerner A. Can Celiac Disease Present Along With Childhood Obesity? Internat J Celiac Dis. 2017;5:19-23.

[17] Lerner A, Makhoul BF, Eliakim R. Neurological manifestations of celiac disease in children and adults. Europ Neurolog J. 2012;4:15-20.

[18] Meseeha MG, Attia MN, Kolade VO. Celiac disease unmasked by acute severe iron deficiency anemia. J Community Hosp Intern Med Perspect. 2016;6:31439.

[19] Zittoun J. Celiac disease revealed by an acute folate deficiency. CESA. Committee of expert for specific investigations in complex anemias. Nouv Rev Fr Hematol. 1989;31:379-82.
[20] Aggarwal V, Kanwal SK, Kumar V, Dhingra B, Kumar P, Chopra A, Kumar S. Acute watery diarrhea: are we missing celiac disease? J Trop Pediatr. 2012 Aug;58(4):329-31.

[21] Bul V, Sleesman B, Boulay B. Celiac Disease Presenting as Profound Diarrhea and Weight Loss - A Celiac Crisis. Am J Case Rep. 2016 Aug 5;17:559-61.

[22] Wolf I, Mouallem M, Farfel Z. Adult celiac disease presented with celiac crisis: severe diarrhea, hypokalemia, and acidosis. J Clin Gastroenterol. 2000;30:324-6.

[23] Kelly E, Cullen G, Aftab AR, Courtney G. Coeliac crisis presenting with cytomegalovirus hepatitis. Eur J Gastroenterol Hepatol. 2006;18:793-5.

[24] Bhattacharya M, Kapoor S. Quadriplegia due to celiac crisis with hypokalemia as initial presentation of celiac disease: a case report. J Trop Pediatr. 2012;58:74-6.

[25] Atikou A, Rabhi M, Hidani H, El Alaoui Faris M, Toloune F. Celiac crisis with quadriplegia due to potassium depletion as presenting feature of celiac disease]. Rev Med Interne. 2009; 30:516-8.

[26] Ojetti V, Fini L, Zileri Dal Verme L, Migneco A, Pola P, Gasbarrini A. Acute cryptogenic liver failure in an untreated coeliac patient: a case report. Eur J Gastroenterol Hepatol. 2005; 17:1119-21.

[27] Al Furaikh S, Al Zaben AA. Recurrent small bowel intussusceptions: an uncommon presentation of celiac disease in an Arab child. Trop Gastroenterol. 2005;26:38-9.

[28] Lastennet F, Piloquet H, Camby C, Moussally F, Siret D.Acute intestinal invagination revealing celiac disease in a 9-month-old infant. Arch Pediatr. 2002;9:151-4.

[29] Grados A, Bernard F, Coquet-Reinier B, Rossi P, Bagneres D, Demoux AL, Marciano S, Frances Y, Granel B. Acute bowel intussusception revealing celiac disease: a new case and literature review Rev Med Interne. 2011;32:628-32.

[30] Quera R, Heine T C, O Brien A, Contreras L. Celiac disease presenting as an intestinal intussusception: report of one case. Rev Med Chil. 2010;138:1276-80.

[31] Galán Bertrand L, Ortiz Ortiz L, Torres Chazarra C, Aleixandre Blanquer F, Ortiz Septien I, Esteban Cantó V, Jover Cerdá J. Acute lithiasic cholecystitis as an exceptional presentation of celiac disease. An Pediatr (Barc). 2006;65:87-8.

[32] González JA, González JB, Crespo MJ, Sancho CI. Acute gallbladder distension and recurrent small bowel intussusception in a child with celiac disease. J Pediatr Gastroenterol Nutr. 1998;27:444-5.

[33] Hijaz NM, Bracken JM, Chandratre SR. Celiac crisis presenting with status epilepticus and encephalopathy. Eur J Pediatr. 2014 Dec;173(12):1561-4.

[34] Schuppan D, Zimmer KP. The diagnosis and treatment of celiac disease. Dtsch Arztebl Int. 2013;110:835-46

[35] Beniwal N, Ameta G, Chahar CK. Celiac Disease in Children with Severe Acute Malnutrition (SAM): A Hospital Based Study. Indian J Pediatr. 2017 ;84:339-343.

[36] Kumar P, Mishra K, Singh P, Rai K. Should we screen children with severe acute malnutrition for celiac disease? Indian Pediatr. 2012;49:330-1.

[37] Tiwari A, Qamar K, Sharma H, Almadani SB. Urinary Tract Infection Associated with a Celiac Crisis: A Preceding or Precipitating Event? Case Rep Gastroenterol. 2017;11:364-368.

[38] Gundling F, Nerlich A, Heitland W, Schepp W. Neuroendocrine pancreatic carcinoma after initial diagnosis of acute postpartal coeliac disease in a 37-year old woman - fatal coincidence or result of a neglected disease? Anticancer Res. 2014;34:2449-54.

[39] Jennings A, Swart S. An acute presentation of coeliac disease in the puerperium. J Obstet Gynaecol. 2007;27:86-7.

[40] Matta R, Aramouni E, Mouawad P, Diab N. Celiac disease presenting as acute colonic pseudo-obstruction. J Med Liban. 2012;60:110-2.

[41] Stoven S, Murray JA, Marietta EV. Latest in vitro and in vivo models of celiac disease.Expert Opin Drug Discov. 2013;8:445-57.

[42] Lindfors K, Rauhavirta T, Stenman S, Mäki M, Kaukinen K. In vitro models for gluten toxicity: relevance for celiac disease pathogenesis and development of novel treatment options. Exp Biol Med (Maywood). 2012;237:119-25.

[43] Stenman SM, Lindfors K, Korponay-Szabo IR, Lohi O, Saavalainen P, Partanen J, et al. Secretion of celiac disease autoantibodies after in vitro gliadin challenge is dependent on 
small-bowel mucosal transglutaminase 2-specific IgA deposits. BMC Immunol. 2008;9:6-13.

[44] Martín-Pagola A, Pérez-Nanclares G, Ortiz L, Vitoria JC, Hualde I, Zaballa R, et al. MICA response to gliadin in intestinal mucosa from celiac patients. Immunogenetics. 2004;56:549-54.
[45] Castellanos-Rubio A, Santin I, Martin-Pagola A, Irastorza I, Castaño L, Vitoria JC, Bilbao JR. Long-term and acute effects of gliadin on small intestine of patients on potentially pathogenic networks in celiac disease. Autoimmunity. 2010;43:131-9. 